\title{
Game-Based Introductory Learning: Teaching Digital Skills to Older Citizens
}

\author{
Mark Springett \\ Middlesex University \\ London NW4 4BT \\ m.springett@mdx.ac.uk
}

\author{
Suzette Keith \\ Middlesex University \\ London NW4 4BT \\ s.keith@mdx.ac.uk
}

\author{
Gill Whitney \\ Middlesex University \\ London NW4 4BT \\ g.whitney@mdx.ac.uk
}

\begin{abstract}
This paper gives a brief description of an exploratory study in which older citizens were introduced to interactive technology by playing games on touch-screens, playing in pairs with the assistance of a mentor. We focus on two principle aspects, the peer-to-peer interaction during these sessions, and the role of the mentor in progressing the sessions. In the case of peer-to-peer interaction we looked for ways in which players supported each other during interaction to assess the role of peer interaction in this context. In the case of mentoring, contrasting approaches taken in the sessions were analysed for their relative efficacy, both in managing instrumental learning, and in fostering confidence and positivity in participants. We found that peer interaction was broadly a positive influence within sessions. Mentors primarily have a strategic role in providing encouragement and support for the flow of exploratory interaction, rather than providing proactive tutoring.
\end{abstract}

Learning, Digital skills, Older citizens, Games.

\section{INTRODUCTION}

The reported work is part of the ERASMUS+ KA2 project 'Gameplay for Inspiring Digital Adoption'. The GIRDA project aims to use social games to address the problem of reluctance and the tendency to withdraw from technology. The environment has a key persuasive role. It is known that many older citizens hold negative attitudes towards technology (Barnard et al 2013), part of which is a perceived inability to learn and master the technology. The weakening of such attitudes is part of the mission, as is the generation of new positive attitudes and re-enactment/reinforcement of positive attitudes. Therefore our approach facilitates a rapid sense of mastery through the use of reality based interaction (Jacob 2008) and providing scaffolding (Wood et al 1976) to provide pathways for accelerated mastery and positive attitudes.

Attitudes may be influenced by events and interventions within interaction. Potential reinforcers of negative attitudes may, for example, be repeated failed actions, erratic and unexplainable system action, or uncomfortable reactions in the social setting. In these situations the scaffolding approach may involve an intervention to weaken the negative consequences of such problems during exploratory interaction.
Positive self-efficacy may be engendered, for example, through appraising achievements through comparison with others (Bandura 1977). This adds value to the more instrumental benefits of joint problem-solving and co-learning through action, such as learning of basic manipulations and interaction principles.

Bandura cites three sources of self-efficacy beliefs that relate to elements of the GIRDA approach, namely enactive mastery experiences, vicarious experiences (comparisons), and verbal persuasions (or similar social influences). Enactive mastery experiences are supported through the use of games. The intrinsic appeal of games and the low pressure associated help lessen perceptions of the task. Playful fascination can motivate users to repeatedly try actions until mastered through practice. Also, where there is an electronic version of a familiar game it may be that positive self-efficacy with regard to that game may override negativity towards technology.

\section{DESCRIPTION OF THE STUDY}

The participants undertook a series of digital games or activities that served to develop gesture based skills such as touch, drag and rotate using a touch screen interface. The mentor was responsible for setting up each of the games and made brief introductions relating to the goal of the 
game rather than the gestures required and was available to offer support when participants appeared stuck, asked questions or system issues affected play. A pre-test questionnaire determined the name, age and prior experiences of the participant and a post-test questionnaire of open and closed questions captured reflections on the experience.

\subsection{Participants}

Each of the project partners set out to recruit 30 people over the age of 50 with no or little prior digital skills, and where possible to balance genders. Altogether 120 people took part in this study with an age range of 57 to 96 (see Table 1).

\subsection{Game Selection}

Each study used a different set of games, but we established a typology of games based on the interaction skill(s) to be learned, and the nature of the social interaction that is facilitated. A further criterion for some games was the familiarity of the game concept (e.g. Solitaire/Patience is a familiar card game for many older people). Games emphasising the tap, drag and rotate actions were chosen. Also, some games could be played by one participant whilst observed by the other. Some games facilitated simultaneous engagement with the table in the same space on the same sub-task. Other games were competitive games. An example of this was the Beetle game in the UK study, which had similar principles to Bowls or Curling (objects flicked towards a target in order to score).

\subsection{Analysis}

The analysis was loosely based on Thematic Analysis (Braun and Clark 2006). Transcripts were taken from video analysis. A set of criteria emerged from a first pass analysis that had been conducted by the UK partners. The criteria were then refined through a comparison with the data collected at the other three sites. They were divided into peer to peer interaction and mentor interventions. The categories are listed in Tables 2 and 3 below and described in section 4.2.

Table 2: Peer to Peer activity

\begin{tabular}{|l|l|}
\hline Category & Description \\
\hline $\begin{array}{l}\text { Independent } \\
\text { activity }\end{array}$ & $\begin{array}{l}\text { No contact or co-ordination } \\
\text { between players }\end{array}$ \\
\hline Copying of partners & mimicry of observed actions \\
\hline Co-learning & $\begin{array}{l}\text { Players discuss and work out } \\
\text { principles whilst playing. }\end{array}$ \\
\hline Co-operative action & $\begin{array}{l}\text { Players work out their roles in a } \\
\text { collaborative task }\end{array}$ \\
\hline Supportive activity & Verbal encouragement \\
\hline
\end{tabular}

Table 3: Mentor Interventions

\begin{tabular}{|l|l|}
\hline Category & Description \\
\hline Requested & Player asks for assistance \\
\hline Proactive & $\begin{array}{l}\text { Mentor recognises an impasse } \\
\text { (e.g. a system breakdown) }\end{array}$ \\
\hline $\begin{array}{l}\text { Supportive } \\
\text { (during) }\end{array}$ & $\begin{array}{l}\text { Verbal encouragement during } \\
\text { play }\end{array}$ \\
\hline $\begin{array}{l}\text { supportive } \\
\text { (post hoc) }\end{array}$ & $\begin{array}{l}\text { Support when a negative self- } \\
\text { evaluation is expressed by a } \\
\text { participant }\end{array}$ \\
\hline
\end{tabular}

\section{FINDINGS}

\subsection{Focus of themes on social interaction}

After we made a first pass analysis of data from the UK pilot sessions, some analysis categories were generated to capture user behaviour and social interaction. Social interaction could include interventions and prompts from the mentor to the participants, peer to peer discussions between the participants and participant to mentor interactions.

Most of the analyses took account of the differences between social interactions and activities, however there are also patterns of exchanges such as a query from the participant followed by a response from the mentor, and completed with an action by the participant.

This higher level analysis points the way to more direct exploration of the impact of particular games, pre-existing skills of the participants and willingness on the part of participants to work together cooperatively.

\subsection{Observed Social Activities}

Peer to Peer Interaction:

This includes independent activity, co-learning (where players discuss and work out principles whilst playing), copying of partners (mimicry of observed actions), co-operative action (where players work out their roles in a collaborative task). This also includes observations of synchronous movement between players, where players respond to physical cues from the other in closely coupled interaction sequences. A further category was supportive activity referring to situations in which one player offers encouragement to the other.

\section{Mentor Intervention:}

A further key category is Intervention, where the mentor sees fit to interject. This could be when verbally requested by a player, when players pause and look at the mentor, or when the mentor proactively recognises a situation that requires intervention (e.g. unexpected system behaviour 
causing the game to disappear). These interventions may be verbal or non-verbal. The following sections describe findings from the four studies.

\section{OBSERVATIONS FROM THE STUDIES}

With the UK study, all sessions were held at the community centres attended by the participants and involved two people working alongside of each other using 32 inch Lenovo Multisurface touch screen. The mentor sat with the participants. Sessions were limited to one hour in which participants typically performed 3 activities, and completed the consent form, and pre and post-test questionnaires.

Independent activity was observed where the participants took the initiative to work on the own, notably in the Drawing activity and the Jigsaw Puzzle which required little in the way of briefing or guidance from the Mentors. In the Drawing app and the Jigsaw Puzzle the participants were able to work independently in parallel.

Supportive activity was observed in situations in which one player offered encouragement to the other or advised on a correct move. In one partnership where only one person knew the rules of Solitaire that partner took on the role of Mentor and directed her partner on which cards to move.

In most of the games there was no enforced turn taking but the participant taking the lead would encourage their partner to take a turn. In the Beetle game when one partner after many failed attempts finally landed a beetle on the target her partner congratulated her.

The mentor was observed intervening to head off negative self-appraisals after errors. For example, after an error made using the drawing application a player declared

"I was waiting for it to clear while I'd got my finger on it. So I went all wrong"

The mentor response was

"Not all wrong, you're just learning".

Co-learning where players discuss and work out principles whilst playing was observed with one pair when they were playing Candy Crush and were trying to understand the rules and which pieces to connect. However there was also an example of a pair of players trying to work out the correct gesture for flicking the beetle onto the target. The particular strategy discussed - a drag gesture - had only partial success when compared to using a flick gesture.
Copying of partners (mimicry of observed actions) was rare. While working side by side there were very few examples of overt copying although some observed their partners closely.

Co-operative action (where players work out their roles in a collaborative task) was more in evidence. The beginner pairs did not tend to articulate their planned actions, but there were examples of nonverbal co-operative activity, such as working together to bring sections of the jigsaw puzzle into alignment.

Synchronous movement between players, where players respond to physical cues from the other in closely coupled interaction sequences, was not observed among the beginner pairs.

The majority of mentor interventions occurred in the game of Solitaire especially where the participants were unfamiliar with the game rules, or had forgotten the rules. As a result the Mentor gave guidance about the game play on a turn by turn basis. Participants also asked questions about the rules and game play of Solitaire.

The Beetle game also provoked questions about the game play and the flick gesture. One pair of participants who were having very limited success and asked if anyone could succeed in the game, and the mentor took a turn at playing a third round of the game, and demonstrated the flick action which the participants then tried to copy.

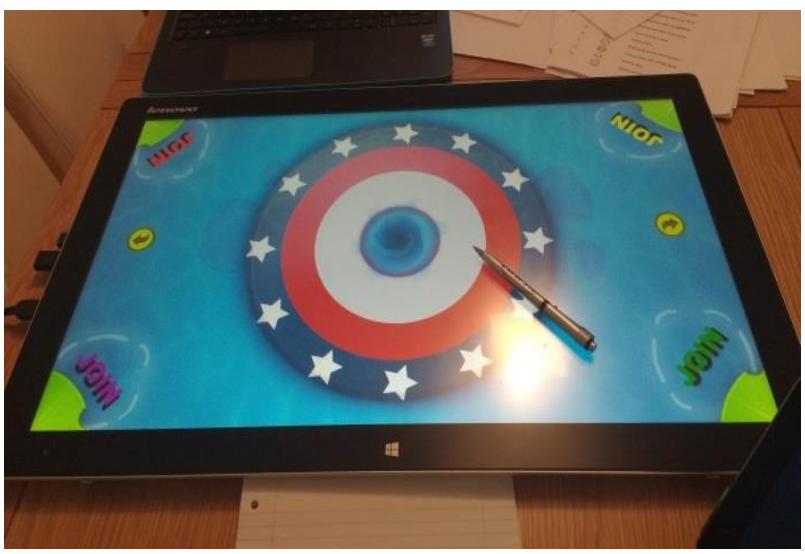

Figure 1: The Beetle Game on the Lenova Multisurface

The mentor also proactively intervened where unexpected system behaviour caused the Jigsaw puzzle to disappear - when the participants activated the poorly positioned menu button, or unintended sweep gestures caused side panels to appear.

\section{8 .CONCLUSIONS AND FUTURE WORK}

Mentoring has a strategic role that primarily involves encouraging rather than explicitly 
instructing users. Providing motional scaffolding seems to be a greater priority than 'tutoring'. In cases where the players reach an impasse this may become more interventionist and more about communicating actions and procedures. Even then the use of hints rather than explicit procedural advice seems to be most effective. Also, the swift intervention of mentors where the behaviour of the device is beyond player comprehension also has a key effect on players. In both cases this can be seen as preserving a sense of flow, as described in (Csikszentmihalyi 2014). Furthermore whilst players are engaged in the flow a game 'task' the hidden instrumental goals of learning how to explore, to plan reactively after errors and to practice key manipulations are supported. The mentor becomes the key figure when the flow is breaking down or threatened by system behaviour.

The distribution of roles in a session changes between players and the mentor. The 'management' of this is another key role of the mentor. This includes supporting a player's attempts to weaken a negative attitude in a partner, or initiating this where a partner has not initiated it. In general we found that partners were often the source of 'interventions' that encourage the generation of positive attitudes or the weakening of negative ones.

Future work will include the design and evaluation of guidelines for those playing the mentor role in introductory sessions. This will include advice on design of the environment, managing the interpartner relationship and selection of suitable games. These themes will be developed in guidance materials to be made available for those organising and conducting such sessions.

\section{ACKNOWLEDGEMENTS}

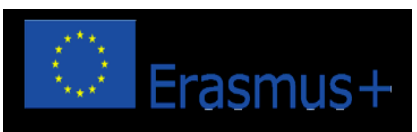

"Co-funded by the Erasmus+ Programme of the European Union."

\section{REFERENCES}

Bandura, A. (1977). Self-efficacy: Toward a unifying theory of behavioral change. Psychological Review, 84, 191-215.

Barnard, Y., Bradley, M. D., Hodgson, F., \& Lloyd, A. D. (2013). Learning to use new technologies by older adults: Perceived difficulties, experimentation behaviour and usability. Computers in Human Behavior, 29(4), 17151724.
Braun, V. and Clarke, V. (2006) Using thematic analysis in psychology. Qualitative Research in Psychology, 3 (2). pp. 77-101 Taylor and Francis

Csikszentmihalyi, M. (2014). Applications of Flow in Human Development and Education: The Collected Works of Mihaly Csikszentmihalyi. Dordrecht: Springer, 2014.

Dickinson, A., Arnott, J., and Prior, S. (2007) Methods for human- computer interaction research with older people, Behaviour \& Information Technology, 26:4, 343-352

Jacob, R. J.K., Girouard, A., Hirshfield, L., et al. (2008). Reality-based interaction: a framework for post-WIMP interfaces. In Proceedings of the SIGCHI Conference on Human Factors in Computing Systems. Florence, Italy, April 5-10, 2008, 201-210. ACM, New York, NY, USA.

Wood, D., Bruner, J. and Ross, G. (1976). The Role of Tutoring in Problem Solving. J Child Psychol Psyc, 17, 89 - 100. 